\title{
AmpC and metallo beta-lactamases producing Gram negative bacteria in patients with hematological malignancy
}

\author{
Samah Sabry El-Kazzaz and Noha Tharwat Abou El-khier* \\ Medical Microbiology and Immunology Department, Faculty of Medicine, Mansoura University, Egypt.
}

Received 18 February, 2015; Accepted 27 April, 2015

\begin{abstract}
Resistance to broad spectrum $\beta$-lactams mediated by AmpC and metallo beta-lactamases (MBLs) enzymes is a rising problem worldwide. The wide dissemination of Gram negative bacteria harboring these enzymes represents a significant clinical threat during the last decade, which is mainly due to treatment failure and restriction of therapeutic options. This problem should be really estimated in our locality with special emphasis on immunocompromised patients. The aim of this study was to isolate Gram negative bacteria from differrent sites of infection among patients with hematological malignancy, and to examine those isolates for AmpC and MBLs production by phenotypic and genotypic methods. Seventy four Gram negative bacterial strains were isolated from 387 clinical samples collected from different infection sites. Those isolates were screened for the presence of AmpC and MBLs by modified three dimensional test and Imipenem-EDTA combined disc test, respectively. Multiplex PCR was done as a confirmatory step for detection of AmpC and MBLs production by these isolates. Pseudomonas aeroginosa was the most common isolated Gram negative strain that was found to be positive for AmpC and MBL production. DHA gene was the most frequently detected AmpC $\beta$-lactamase gene, whereas VIM was the only detected MBL gene among the Gram negative bacterial isolates by multiplex PCR. The strong association found between AmpC production and MBL gene carriage is alarming which necessitate continuous surveillance of such resistance mechanisms among the Gram negative bacteria, especially in patients with hematological malignancy.
\end{abstract}

Key words: $\mathrm{AmpC}$, metallo beta-lactamase (MBL), multiplex polymerase chain reaction, Pseudomonas aeroginosa.

\section{INTRODUCTION}

$\beta$-Lactamases are important components of the antimicrobial resistance in Gram negative bacteria. They are identified in these pathogens as well as their biochemical properties (Zavasci et al., 2010). These enzymes inactivate cephalosporins and penicillins by hydrolyzing the amide bond of the $\beta$-lactam ring. Molecular class $C$ or AmpC

*Corresponding author. E-mail: nohat75@yahoo.com.

Author(s) agree that this article remains permanently open access under the terms of the Creative Commons Attribution License 4.0 International License 
primarily hydrolyses cephems (cephamycins and cephalosporins) and also hydrolyze penicillins and aztreonam. These enzymes are resistant to the currently available $\beta$-lactamase inhibitors such as clavulanate, sulbactam and tazobactam (Philippon et al., 2002). With rare exceptions, the hydrolysis of cephamycins, such as cefoxitin and cefotetan, is a property that can help to distinguish AmpCs from extended-spectrum beta lactamase (ESBLs).

High level production of AmpC by Gram negative bacteria may cause resistance to the first, second and third-generation cephalosporins, penicillins, cephamycins and $\beta$-lactamase inhibitor combination. Higher level AmpC production may occur as a consequence of mutation or when the organism is exposed to an inducing agent. Cephamycins (e.g. cefotetan and cefoxitin), ampicillin, and carbapenem are good inducers (Moland et al., 2008).

Carbapenamases are $\beta$-lactamases, which include serine- $\beta$ - lactamases (OXA, KPC, GES, etc.) and MBLs. The latter require metal ion zinc for their activity, which is inhibited by metal chelators like EDTA and thiol-based compounds but not by tazobactam, sulbactam and clavulanic acid. MBL producing Gram negative bacteria are typically resistant to aminoglycosides and fluoroquinolones, further compromising therapeutic options (Uma Karthika et al., 2009).

Among several types of $\mathrm{MBL}$ genes described throughout the world, bla- VIM, bla- IMP and bla-NDM are the most common (Amudhan et al., 2011). The genes responsible for MBL production may be chromosomal or plasmid mediated and poses a threat of horizontal transfer among other Gram-negative bacteria (Varaiya et al., 2008).

Infections remain a common complication in patients with hematological malignancies. These patients are at higher risk of infections not only because of the malignancy itself but also because of neutropenia induced by intensive chemotherapeutic therapy that may be followed by hematopoietic stem cell transplantation, and the cytotoxic effect on the cells that line the alimentary tract (Crawford et al., 2004).

It was demonstrated that $60 \%$ of the bacteraemias in neutropenic patients were caused by Gram negative bacterial infections (Chen et al., 2010). Moreover, the increased rates of drug resistant Gram-negative pathogens which was documented globally (Bhusal et al., 2011), including ESBLs, AmpC and carbapenemase producing Gram-negative bacteria isolates (Freifeld et al., 2011) and despite of the improved survival rate during the last decades, patients with haematological malignancies are still at high risk of infectious complications. Bacteraemia caused by beta-lactamase producing Gram negative bacteria are serious complications and the use of prophylaxis may lead to a higher prevalence of more resistant strains (Nørgaard, 2012). So the aim of this study was to detect Gram negative bacterial infection among these patients and to examine the bacterial isolates for AmpC and MBLs production by phenotypic and genotypic methods.

\section{MATERIALS AND METHODS}

\section{Study design}

Descriptive cross sectional study was carried out on 373 patients with heamatological malignancy over a period of six months from first of June to the end of November, 2013. All patients, enrolled in this study, were admited in the Oncology Centre of Mansoura University Hospitals (MUHs).

\section{Clinical samples}

387 clinical samples collected from different infection sites included 139 urine, 95 sputum, 86 blood and 67 wound swabs.

\section{Microbiological studies}

Samples were processed in Microbiology Diagnostic and Infection Control Unit (MDICU) in Medical Microbiology and Immunology Department, Faculty of Medicine, Mansoura University. The collected blood, sputum and wound specimens were cultivated on blood agar, macConkey's agar and chocolate agar media, whereas urine specimens were cultivated on CLED media. Gram negative bacterial isolates was identified by Gram stained films, colony morphology and different biochemical reactions.

\section{Antibiotic susceptibility testing}

Antimicrobial susceptibility was tested for the identified Gram negative isolates according to CLSI recommendations. The diffusion method on Mueller-Hinton agar (MHA; Bio-Rad, MarnesLa-Coquette, France) was used to test susceptibility to Ampicilline ,Amoxicilline/Clavulinic acid, Cefotaxime, Azteronam, Imipenem, Pipracilline, pipracilline/Tazobzctam, Amikacin, Ciprofloxacin, Gentamicin, Ceftazidime (Koneman et al., 1997).

\section{Phenotypic detection of $\mathrm{AmpC}$ by modified three dimensional test (Taneja et al., 2008)}

Crude enzyme extract was prepared by repeated freezing and thawing of the bacterial pellet of each Gram negative bacterial isolate (five to seven times). Lawn culture of Escherichia coli ATCC 25922 was prepared on Muller Hinton plates and Cefoxitin $(30 \mu \mathrm{g})$ disk were placed on the plates. Linear slits $(3 \mathrm{~cm})$ were cut using sterile surgical blade, $3 \mathrm{~mm}$ away from cefoxitin disk. At the other end of the slit, a small circular well was made and 30 to $40 \mu \mathrm{l}$ of the enzyme extract was loaded in the well. Then, the plates were incubated at $37^{\circ} \mathrm{C}$ for $24 \mathrm{~h}$. Enhanced growth of the surface organism at the point where the slit inserted the zone of inhibition of cefoxitin was considered a positive modified three dimensional test. Isolates showing clear distortion of the zone of inhibition of cefoxitin were considered as AmpC producers.

Phenotypic detection of MBL by Imipenem-EDTA combined disc method (Yong et al., 2002):

A $0.5 \mathrm{M}$ EDTA solution was prepared by dissolving $186.1 \mathrm{~g}$ of 
Table 1. Primers used in multiplex PCR and PCR mapping in this study.

\begin{tabular}{|c|c|c|c|}
\hline Primer & Sequence 5'-3' & Amplicon size (bp) & Reference \\
\hline MultiCaseACC_for & CACCTCCAGCGACTTGTTAC & \multirow{2}{*}{346} & \multirow{14}{*}{ Dallenne et al., 2010} \\
\hline MultiCaseACC_rev & GTTAGCCAGCATCACGATCC & & \\
\hline MultiCaseFOX_for & CTACAGTGCGGGTGGTTT & \multirow{2}{*}{162} & \\
\hline MultiCaseFOX_rev & CTATTTGCGGCCAGGTGA & & \\
\hline MultiCaseMOX_for & GCAACAACGACAATCCATCCT & \multirow{2}{*}{895} & \\
\hline MultiCaseMOX_rev & GGGATAGGCGTAACTCTCCCAA & & \\
\hline MultiCaseDHA_for & TGATGGCACAGCAGGATATTC & \multirow{2}{*}{997} & \\
\hline MultiCaseDHA_rev & GCTTTGACTCTTTCGGTATTCG & & \\
\hline MultiCaseCIT_for & CGAAGAGGCAATGACCAGAC & \multirow{2}{*}{538} & \\
\hline MultiCaseCIT_rev & ACGGACAGGGTTAGGATAGYb & & \\
\hline MultiCaseEBC_for & CGGTAAAGCCGATGTTGCG & \multirow{2}{*}{683} & \\
\hline MultiCaseEBC_rev & AGCCTAACCCCTGATACA & & \\
\hline MultilMP_for & TTGACACTCCATTTACDG ${ }^{\mathrm{b}}$ & \multirow{2}{*}{139} & \\
\hline MultilMP_rev & GATYGAGAATTAAGCCACYCT ${ }^{b}$ & & \\
\hline MultiVIM_for & GATGGTGTTTGGTCGCATA & \multirow{2}{*}{390} & \multirow{2}{*}{ Ellington et al., 2007} \\
\hline MultiVIM_rev & CGAATGCGCAGCACCAG & & \\
\hline MultiNDM_for & GGTTTGGCGATCTGGTTTTC & \multirow{2}{*}{621} & \multirow{2}{*}{ Anoar et al., 2014} \\
\hline MultiNDM_rev & CGGAATGGCTCATCACGATC & & \\
\hline
\end{tabular}

${ }^{\mathrm{b}} \mathrm{Y}=\mathrm{T}$ or $\mathrm{C} ; \mathrm{D}=\mathrm{A}$ or $\mathrm{G}$ or $\mathrm{T}$.

disodium EDTA $2 \mathrm{H} 2 \mathrm{O}$ in $1000 \mathrm{ml}$ of distilled water and adjusting it to $\mathrm{pH} 8.0$ by using $\mathrm{NaOH}$. The mixture was sterilized by autoclaving. One disc of imipenem $(10 \mu \mathrm{g})$ alone and one with imipenem $(10 \mu \mathrm{g})$ in combination with EDTA solution were placed at a distance of $20 \mathrm{~mm}$, from center to center, on a Muller Hinton agar plate inoculated with a bacterial suspension of $0.5 \mathrm{McF}$ arland turbidity standards of each Gram negative bacterial isolate. The plates are incubated overnight at $35^{\circ} \mathrm{C}$. The $\mathrm{MBL}$ producing strains showed a variation greater than $7 \mathrm{~mm}$ between the inhibition zone around imipenem discs alone and the inhibition zone around imipenem+ EDTA discs, (the imipenem + EDTA discs shows larger zone of inhibition than imipenem disc alone in $\mathrm{MBL}$ positive strains).

Detection of plasmid encoded AmpC and MBL genes by
multiplex PCR

\section{Design of group-specific primers for multiplex PCR assays}

Two multiplex PCRs were designed in this study: a plasmidmediated AmpC $\beta$-lactamase gene multiplex PCR including six family-specific AmpC genes carried on the plasmids, which are ACC, FOX, MOX, DHA, CIT and EBC (Perez-Perez and Hanson, 2002); and MBL gene multiplex PCRs, including blavIM, bla $a_{\mathrm{IMP}}$ and blandM genes (Amudhan et al., 2011). Group-specific primers were designed to amplify internal fragments of several sizes (Table 1).

\section{Multiplex PCR technique (Dallenne et al., 2010)}

Rapid DNA preparation was performed from one heated colony in a total volume of $100 \mathrm{~mL}$ of distilled water $\left(95^{\circ} \mathrm{C}\right.$ for $\left.10 \mathrm{~min}\right)$ followed by a centrifugation step of the cell suspension. Total DNA $(2 \mathrm{~mL})$ was subjected to each multiplex $\mathrm{PCR}$ in a $50 \mathrm{~mL}$ reaction mixture containing $1 \times \mathrm{PCR}$ buffer $(10 \mathrm{mM}$ Tris $-\mathrm{HCl}$, $\mathrm{pH} 8.3 / 50 \mathrm{mM} \mathrm{KCl} / 1.5$ $\mathrm{mM} \mathrm{MgCl}$ ), $200 \mathrm{mM}$ concentration of each deoxynucleotide triphosphate, a variable concentration of specific-group primers
(Table 1) and $1 \mathrm{U}$ of Taq polymerase (Fermentas). Amplification was carried out as follows: initial denaturation at $94^{\circ} \mathrm{C}$ for $10 \mathrm{~min}$; 30 cycles of $94^{\circ} \mathrm{C}$ for $40 \mathrm{~s}, 60^{\circ} \mathrm{C}$ for $40 \mathrm{~s}$ and $72^{\circ} \mathrm{C}$ for $1 \mathrm{~min}$; and a final elongation step at $72^{\circ} \mathrm{C}$ for $7 \mathrm{~min}$. For the MBL genes multiplex PCR assays, the annealing temperature was optimal at $55^{\circ} \mathrm{C}$ for amplification of blavim, bla IMP and bla NDM $_{\text {I }}$ genes. Amplicons were visualized after running at $100 \mathrm{~V}$ for $1 \mathrm{~h}$ on a $2 \%$ agarose gel containing ethidium bromide. A 100 bp DNA ladder (\#SMO323 marker "Fermentas") was used as a size marker.

\section{Data analysis}

Data were entered and statistically analyzed using Statistical Package of Social Science (SPSS) software version 17. Qualitative data were described as numbers and percentages.

\section{RESULTS}

Out of the 387 clinical samples, 74 Gram negative bacterial isolates were detected, including 26 Klebsiella spp., 19 E. coli, 16 pseudomonas aeruginosa, 11 Proteus spp. and 2 Citrobacter spp. Urine was the most common source of the isolated Gram negative bacteria (42\%), followed by sputum (28\%), wound (18\%) and blood $(12 \%)$.

Percentage of resistance exhibited by the 74 Gram negative bacterial isolates to various antimicrobial agents is shown in (Table 2). AmpC was detected in 38 (51.3\%) of the 74 Gram negative bacterial isolates which were studied in this research. Among the 16 Pseudomonas aeruginosa isolates, 15 (93.7\%) isolates were found to be 
Table 2. Antibiotic resistance pattern of the Gram negative bacterial isolates.

\begin{tabular}{|c|c|c|c|c|c|c|c|c|c|c|}
\hline \multirow[t]{2}{*}{ Bacterial isolates } & \multicolumn{2}{|c|}{$\begin{array}{c}\text { Pseudomonas } \\
\text { aeroginosa }\end{array}$} & \multicolumn{2}{|c|}{$\begin{array}{c}\text { Klebsiella } \\
\text { spp }\end{array}$} & \multicolumn{2}{|c|}{ E. coli } & \multicolumn{2}{|c|}{$\begin{array}{c}\text { Proteus } \\
\text { spp }\end{array}$} & \multicolumn{2}{|c|}{$\begin{array}{c}\text { Citrobacte } \\
\text { spp }\end{array}$} \\
\hline & $\mathbf{R}$ & $\%$ & $\mathbf{R}$ & $\%$ & $\mathbf{R}$ & $\%$ & $\mathbf{R}$ & $\%$ & $\mathbf{R}$ & $\%$ \\
\hline Ampicilline & 16 & 100 & 24 & 92.3 & 18 & 94.7 & 11 & 100 & 2 & 100 \\
\hline Amoxicilline/Clavulinic acid & 12 & 75 & 16 & 61.5 & 16 & 84.2 & 8 & 72.7 & 1 & 50 \\
\hline Azteronam & 7 & 43.7 & 9 & 34.6 & 8 & 42.1 & 9 & 81.8 & 1 & 50 \\
\hline Cefotaxime & 15 & 93.7 & 19 & 73 & 10 & 52.6 & 9 & 81.8 & 2 & 100 \\
\hline Imipenem & 9 & 56.2 & 8 & 30.7 & 11 & 57.9 & 6 & 54.5 & 1 & 50 \\
\hline Pipracilline & 11 & 68.7 & 7 & 26.9 & 17 & 89.4 & 11 & 100 & 2 & 100 \\
\hline pipracilline/Tazobzctam & 8 & 50 & 6 & 23 & 12 & 63.1 & 7 & 63.6 & 0 & 0 \\
\hline Amikacin & 14 & 87.5 & 14 & 53.8 & 13 & 68.4 & 8 & 72.7 & 1 & 50 \\
\hline Ciprofloxacin & 12 & 75 & 22 & 84.6 & 14 & 73.6 & 10 & 90.9 & 2 & 100 \\
\hline Gentamicin & 15 & 93.7 & 17 & 65.3 & 14 & 73.6 & 9 & 81.8 & 2 & 100 \\
\hline Ceftazidime & 14 & 87.5 & 20 & 76.9 & 11 & 57.9 & 11 & 100 & 2 & 100 \\
\hline
\end{tabular}

spp: Species, R: Resistant, \%: percentage

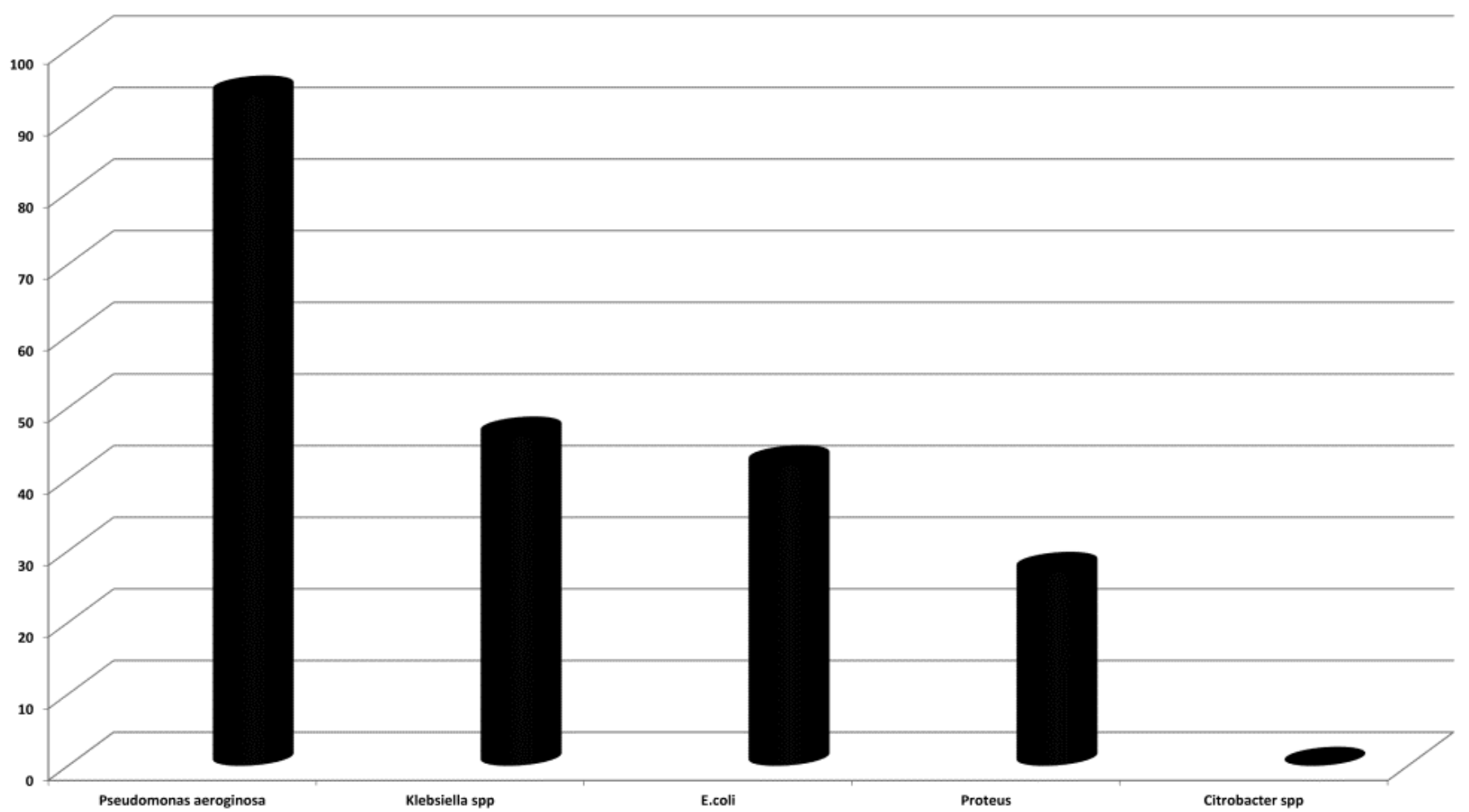

Figure 1. Percentage of AmpC production among the Gram negative bacterial isolates.

positive for AmpC production by modified 3 dimentional test. Whereas $12(46.1 \%)$ isolates of Klebsiella, 8 (42.1\%) isolates of E. coli, $3(27.2 \%)$ isolates of Proteus spp. and none of Citrobacter spp. were found to be positive by the same test, (Figures 1 and 2).

MBL was detected in $20(27 \%)$ of the studied 74 Gram negative bacterial isolates. It was present in 11 (68.7\%), 7 (26.9\%), 2 (18.1\%) of Pseudomonas aeruginosa, Klebsiella spp. And Proteus spp. respectively by imipenem-EDTA disc method, (Figure 3), whereas none of E.coli and Citrobacter spp. were found to be positive by the same test. 


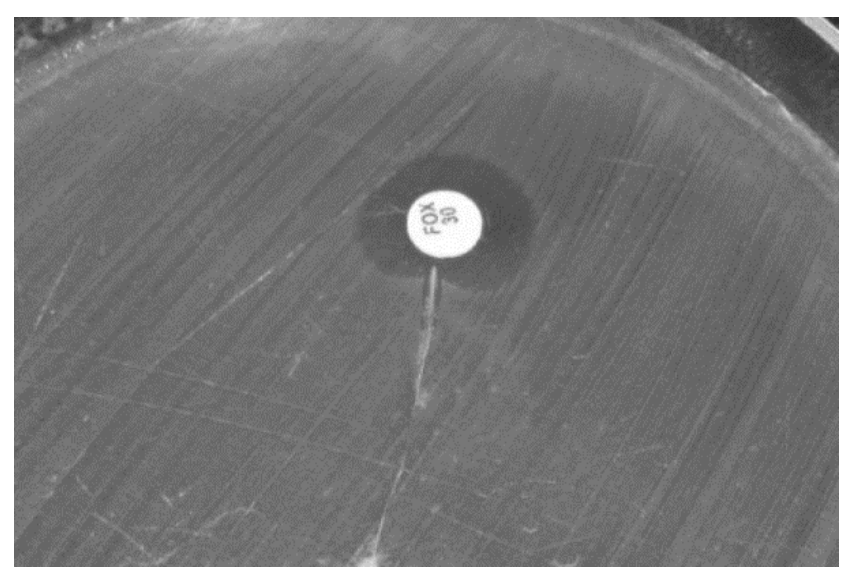

Figure 2. Positive modified three dimensional test for one of the isolated Gram negative bacteria. Enhanced growth of the surface organism, E. coli ATCC25922, is seen near the agar slit that contain extract of the Gram negative bacterial isolate.

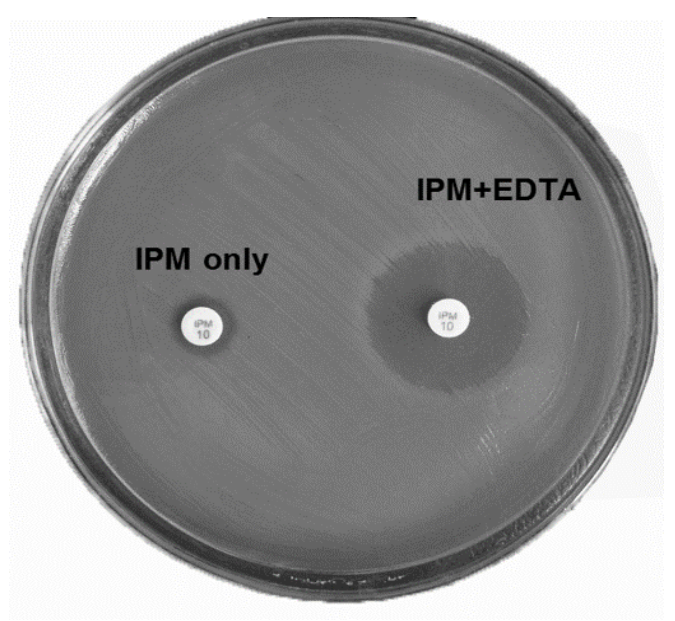

Figure 3. Positive imipenem-EDTA combined disc test for one of the isolated Gram negative bacteria. The imipenem + EDTA discs shows larger zone of inhibition than imipenem disc alone.

As regarding the result of multiplex PCR assay (Figure 4), that was performed for the strains that were positive for AmpC and MBL by phenotypic detection methods, it was found that, plasmid-mediated AmpC $\beta$-lactamase genes were detected in $31(81.5 \%)$ of the $38 \mathrm{AmpC}$ positive Gram negative bacterial isolates, whereas only $12(60 \%)$ of the $20 \mathrm{MBL}$ producing isolates were found to be positive for MBLs genes, and we observed 5 isolates that were positive for both AmpC $\beta$-lactamase and MBLs genes.

DHA genes was the most frequently observed plasmid mediated AmpC $\beta$-lactamases (found in 23 isolates, "60.5\%"); whereas 5 isolates, "13.1\%" and only 3 , isolates "7.8\%" were found to be positive for CIT and ACC genes group, respectively.

VIM genes were the only detected MBLs gene among the studied bacterial isolates by multiplex PCR, whereas, no isolates were found to be positive for IMP or NDM genes.

\section{DISCUSSION}

The clear role of Gram negative bacteria in the production of various $\beta$-lactamase enzymes have been reported with an increasing frequency as an important hospital problem because they are associated with high morbidity and mortality rates (Itokazu et al., 1996).

Initially these enzymes were commonly found in Klebsiella species and E. coli (Mathur et al., 2002), but now they are produced by all the members of Enterobacteriaceae and other Gram negative bacteria (Kumar et al., 2006). These enzymes are capable of hydrolyzing broad spectrum cephalosporins and monobactams and inactive against imipenem and cephamycins (Albertini, 2002).

It was documented that bacteraemias in neutropenic patients were mostly caused by Gram negative infections (Chen et al., 2010) and a similar pattern was demonstrated by Gupta et al. (2010) in a study from India. Gram-negative bacterial strains (E. coli, Klebsiella spp. and $P$. aeruginosa) were the predominant infectious bacteria in neutropenic cancer patients in the 1970s and early 1980s (Carratala and Gudiol, 2000). These findings confirm the role of Gram negative bacteria as a source of different types of enzymes that induce high degree of resistance, particularly AmpC and MBLs in those patients that could badly affect their outcome and survival.

AmpC $\beta$-lactamases are cephalosporinases which are encoded on chromosomes of many of the Enterobacteriaceae and a few other organisms, and they mediate resistance to cephalothin, cefoxitin, cefazolin, most of the penicillins and $\beta$-lactamase inhibitor. AmpC enzymes are inducible and can be expressed at high levels by mutation in different types of Gram negative bacteria. Over expression can induce resistance to broad spectrum cephalosporins (Black et al., 2005).

In this study, $51.3 \%$ of the Gram negative isolates were AmpC producer and $P$. aeruginosa was the predominant AmpC producing strain. These results were in agreement with Altun et al. (2013), who found that all the studied $P$. aeruginosa isolates were $\mathrm{AmpC}$ producer. On the other hand, lower percentage of AmpC production among $P$. aeruginosa isolates (72.4 and $59.4 \%$ ) was reported by Abd El-Baky et al. (2013) and Upadhyay et al. (2010) respectively.

The discrepancy among different studies could be attributed to different localities where each one has its own pattern of pathogens distribution and resistance.

MBL is a group of carbapenem hydrolysing $\beta$ lactamase (Chu et al., 2001). They have been reported in 


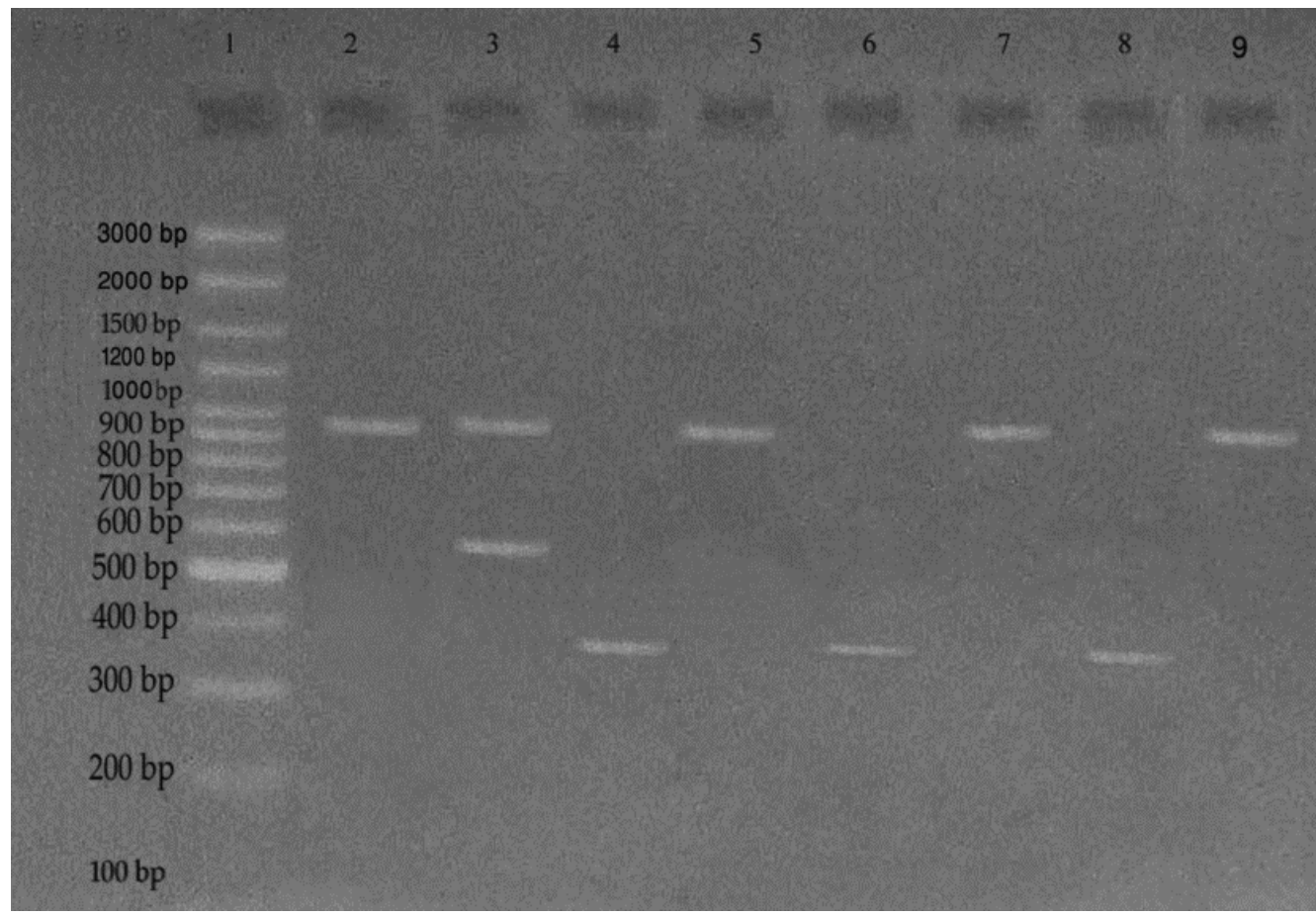

Figure 4. The results of the multiplex PCR assay of the Gram negative bacterial isolates. The figure shows the multiplex PCR results with primers specific for AmpC and MBLs genes. Lane 1 shows molecular size marker \#SMO323. Lanes 2, 3, 5, 7 and 9 shows bands of 997 base pair from positive strains that carry the DHA genes, whereas lanes 4, 6 and 8 shows bands of 390 base pair from positive strains that carry the VIM genes and lane 3 shows band of 538 base pair of the CIT gene.

multidrug resistance pathogens like $P$. aeruginosa and Acinetobacter species. The MBLs are inhibited in vitro by $\mathrm{CuCl}_{3}, \mathrm{FeCl}_{3}$, EDTA and thiol compounds, but not by $\beta$ lactamase inhibitors like Clavulanic acid, Sulbactum or Tazobactam (Goossens, 2000). Detection of MBL production in Gram negative bacteria from patients with hematological malignancy has tremendous therapeutic consequences, as the treatment option for such isolates are aztreonam or potentially toxic polymyxin B and colistin.

In the present study, MBL was detected by imipenemEDTA disc method in $20 \%$ of the studied isolates and $P$. aeruginosa was also the predominant $\mathrm{MBL}$ producing strain (68.7\%). Similarly, Noyal et al. (2009) stated that $50 \%$ of the studied $P$. aeruginosa strains were positive for $\mathrm{MBL}$ by the same test and it was the most common MBL producing strain among his studied Gram negative bacterial isolates. On the other hand, our results are dissimilar with that of Mishra et al. (2012) and Altun et al. (2013), who found that Acinitobacter were the most common MBLs producing strains in their study, and reported a higher incidence of MBL production than $P$. aeruginosa strains.

$P$. aeruginosa may be intrinsically resistant or have acquired resistance to antibiotics due to permeability barrier of the cell surface, multidrug efflux pumps and production of $\beta$-lactamases (AmpC $\beta$-lactamase, extended spectrum $\beta$-lactamases and metallo- $\beta$-lactamases) (Pai et al., 2004). Multiple beta-lactamase producing $P$. aeruginosa can cause major therapeutic failure, and poses a significant clinical threat if remain undetected. Therefore, early identification of the infections due to these microorganisms is necessary as the appropriate treatment might reduce the spread of these resistant strains as well as the mortality in hospitalized patients. This emphasizes the need for the detection of isolates that produce these enzymes to avoid therapeutic failures and nosocomial outbreaks in hospitals (Kumar et al., 2012).

In our study, 93.7 and $68.7 \%$ of $P$. aeruginosa strains were positive for AmpC and $\mathrm{MBL}$ respectively. Carbapenems were the effective antibiotics for MDR Gram-negative bacteria infections, especially in high-risk hospital settings, particularly, $P$. aeruginosa (Deshpande et al., 2010). Therefore, when administering empirical treatment in patients with hospital-acquired infections due to Pseudomonas spp., if patients do not respond to carbapenem therapy, MBL should be considered.

Multiplex PCR is one of the most important diagnostic methods that is used to determine the most frequent widespread $\beta$-lactamase genes encoding plasmidmediated AmpC and MBLs, PCR is a fast, low-cost and It helps in monitoring the emergence of those genes and their spread, and it could also be used in epidemiological 
surveys.

DHA genes was the most frequently observed plasmid mediated AmpC $\beta$-lactamases (found to be $60.5 \%$ ) of the studied AmpC positive strains, whereas VIM genes was the only detected MBLs genes among the studied bacterial isolates by multiplex PCR. Our results were consistent with the finding of Dallenne et al. (2010), who reported that, DHA enzymes were the most frequently observed AmpC $\beta$-lactamases among their studied isolates, but in their study, they did not find any of the MBLs genes that were targeted. Parallel to our finding, Chakraborty et al. (2011), found that most of the studied strains were found to amplify the VIM primer and no IMP genes got amplified.

On the other hand, our results were dissimilar with that of Manoharan et al. (2012), who mentioned that CIT and FOX were the most frequently detected AmpC $\beta$ lactamases genes, whereas DHA was the least frequently detected one. Also contrary to our findings, Anoar et al. (2014), observed IMP as the most frequently found MBL gene among their studied isolates and it recorded a higher percentage of detection than VIM and NDM genes.

In our research, the percent of strains that carried AmpC and MBL genes was higher than those reported in previous studies. The reasons may be an overall increase in the extent of acquirement of AmpC and MBLs genes among $P$. aeruginosa, which was highly isolated in this study plus its high resistance pattern which is characteristic in our locality. Moreover, the location of AmpC and MBL genes on plasmide and on class I integron respectively, can therefore easily transfer between the Gram negative bacterial isolates particularly, $P$. aeruginosa strains (Cornaglia et al., 2000).

Of the MBL phenotypic-positive isolates, 8 did not carry the MBL genes. It may be possible that these isolates harbor other MBL genes that were not detected in this study. Another possibility may be the susceptibility of some bacterial strains to EDTA, which can affect bacterial membrane permeability, leading to false positive results for the MBL phenotypic tests (Aktas and Kayacan, 2008). Also, sizeable number of isolates were not positive for AmpC production by the multiplex PCR, but they were phenotypically positive, this warrants further molecular investigation into the other mechanisms of resistance and their laboratory detection.

Although the modified three dimensional test and Imipenem-EDTA combined disc test reliably detected AmpC and MBL when compared with the PCR in the present study, clinical laboratories interested in distinguishing $\mathrm{AmpC}$ and $\mathrm{MBL}$ mediated resistance from other $\beta$-lactamase resistance mechanisms will need to use combination of phenotypic and molecular identification methods, and we thought that the multiplex PCR technique described in this study will be an important tool for the detection of AmpC $\beta$-lactamases and MBL genes in Gram-negative bacteria.

\section{Conclusion}

Despite the discovery of $\mathrm{AmpC}$ and $\mathrm{MBL}$ at least a decade ago, there remains a low level of awareness of their medical importance and many clinical laboratories have problems in detecting them. On the other hand, the strong association found between AmpC production and $\mathrm{MBL}$ gene carriage is alarming and would limit the choice of antibiotic treatment even more. So, this study findings indicate the necessity for continuous surveillance of such resistance mechanisms among the Gram negative bacteria and evolve preventive measures aimed at reducing their spread among patients with hematological malignancy.

\section{Conflict of interests}

The author(s) did not declare any conflict of interest.

\section{REFERENCES}

Abd El-Baky RM, Abd El-Azeim NH, Gad GFM (2013). Prevalence of Extended-Spectrum Beta-Lactamase, AmpC Beta- Lactamase, and Metallo-Beta-Lactamase among Clinical Isolates of Pseudomonas aeruginosa. J. Adv. Biotechnol. BioEng. 1:22-29.

Aktas Z, Kayacan, CB (2008). Investigation of metallo- $\beta$-lactamase producing strains of Pseudomonas aeruginosa and Acinetobacter baumanni by E-test, disk synergy, and PCR. Scand. J. Infect. Dis. 40:320-325.

Albertini MT (2002). Surveillance of methicillin-resistant Staphylococcus aureus (MRSA) and Enterobacteriaceae producing extendedspectrum beta lactamase (ESBLE) in Northern France: a five-year multicentre incidence study. J. Hosp. Infect. 52(2):107-113.

Altun S, Tufan ZK, Yağcı S, Önde U, Bulut C, Kınıkl S, Demiroz AP (2013). Extended Spectrum Beta-lactamases, AmpC and Metallo Beta-lactamases in Emerging Multi-drug Resistant Gram-negative Bacteria in Intensive Care Units.Open. Access. Scientific. Reports, 2:4.

Amudhan SM, Sekar U, Arunagiri K, Sekar B (2011). OXA betalactamase-mediated carbapenem resistance in Acinetobacter baumannii. Indian. J. Med. Microbiol. 29:269-274.

Anoar KA, Ali FA, Omer SA (2014). Detection of Metallo B- lactamase enzyme in some Gram Negative Bacteria isolated from Burn Patients in Sulaimani City, Iraq. European. Sci. J. 10:3. ISSN: 1857 - 7881 (Print) e - ISSN 1857- 7431.

Bhusal Y, Mihu CN, Tarrand JJ, Rolston KV (2011). Incidence of fluoroquinolone-resistant and extended-spectrum beta-lactamase producing Escherichia coli at a comprehensive cancer center in the United States. Chemother. 57:335-338.

Black JA, Moland ES, Thomson KS (2005). Amp C disk test for detection of plasmid mediated Amp C $\beta$-lactamases. J. Clin Microbiol. 43(7):3110- 3113.

Carratala J, Gudiol F (2000). Changing epidemiology of bacterial infection in neutropenic patients with cancer. Antibiot. Chemother. $50: 1-9$.

Chakraborty D, Basu S, Das S (2011). Study on some Gram negative multidrug resistant bacteria and their molecular characterization. Asian. J. Pharmaceut. and Clin. Res. 4(1):108-112. ISSN- 09742441.

Chen CY, Tsay W, Tang JL, Tien HF, Chen YC, Chang SC, Hsueh, PR (2010). Epidemiology of bloodstream infections in patients with haematological malignancies with and without neutropenia Epidemiol. Infect. 138:1044-1051.

Chu YWM, Afzal-Shah ETS, Houang MFI, Palepou DJ, Lyon N Woodford, Livermore DM (2001). IMP-4, a novel metallo- $\beta$-lactamase from nosocomial Acinetobacter spp. collected in Hong Kong between 
1994 and 1998. Antimicrob. Agents. Chemother. 45:710-714.

Cornaglia G, Mazzariol A, Lauretti L, Rossolini GM, Fontana R (2000). Hospital outbreak of carbapenem-resistant Pseudomonas aeruginosa producingVIM-1, a novel transferable metallo- $\beta$-lactamase. Clin. Infec. Dis. 31(5):1119-1125.

Crawford J, Dale DC, Lyman GH (2004). Chemotherapy-induced neutropenia: risks, consequences, and new directions for its management. Cancer. 100: 228-37.

Dallenne C, Da Costa A, Decre A, Favier C, Arlet G (2010). Development of a set of multiplex PCR assays for the detection of genes encoding important b-lactamases in Enterobacteriaceae. J. Antimicrob. Chemother. doi:10.1093/jac/dkp498.

Deshpande P, Rodrigues C, Shetty A, Kapadia F, Hedge A, Soman, R (2010). New Delhi Metallo-beta lactamase (NDM-1) in Enterobacteriaceae: treatment options with carbapenems compromised. J. Assoc. Phys. 58:147-149.

Ellington MJ, Kistler J, Livermore DM, Woodford N (2007). Multiplex PCR for rapid detection of genes encoding acquired metallo-blactamases. J. Antimicrob. Chemother. 59:321-322.

Freifeld AG, Bow EJ, Sepkowitz KA, Boeckh MJ, Ito JI, Mullen CA, Raad II, Rolston KV, Young JAH, Wingard JR (2011). Clinical practice guideline for the use of antimicrobial agents in neutropenic patients with cancer: 2010 Update by the Infectious Diseases Society of America. Clin. Infect. Dis. 52:427-431.

Goossens H MYSTIC (Meropenem Yearly Susceptibility Test Information Collection) (2000). (Meropenem Yearly Susceptibility Test Information Collection) results from Europe: comparison of antibiotic susceptibilities between countries and centre types. J. Antimicrob. Chemother. 46:39-52.

Gupta A, Singh M, Singh H, Kumar L, Sharma A, Bakhshi S, Raina V, Thulkar S (2010). Infections in acute myeloid leukemia: an analysis of 382 febrile episodes. Med. Oncol. 27:1037-1045.

Itokazu G, Quinn JP, Bell-Dixon C, Kahan FM, Weinstein RA (1996). Antimicrobial resistance rates among aerobic gram-negative bacilli recovered from patients in intensive care units: evaluation of a national post marketing surveillance program. Clin. Infect. Dis. 23:779-784

Koneman EW, Allen SD, Janda WA, Schreckenberger RC, Winn WC (1997). Antimicrobial susceptibility testing. In : Koneman EW, Allen SD, Janda WA, Schreckenberger RC, Winn WC (Eds.) : Color Atlas and Text book of Diagnostic Microbiology, ( $5^{\text {th }}$ ed). Philadelphia. Lipincott. Raven. pp. 785- 856.

Kumar MS, Lakshmi V, Rajagopalan R (2006). Occurrence of extended spectrum $\beta$ - lactamases among Enterobacteriaceae species isolated at a tertiary care institute. Indian. J. Med. Microbiol. 24(3): 208-11.

Kumar V, Sen MR, Nigam C, GahlotKumari S (2012). Burden of different beta-lactamase classes among clinical isolates of AmpCproducing Pseudomonas aeruginosa in burn patients: A prospective study. Indian. J. Crit. Care. Med. 16:136-140.

Manoharan A, Sugumar M, KumarA, Jose H, Mathai D,\&ICMR-ESBL study group (2012). Phenotypic \& molecular characterization of AmpC $\beta$-lactamases among Escherichia coli, Klebsiella spp. \&Enterobacter spp. from five Indian Medical Centers. Indian. J. Med. Res. 135: 359-364.
Mathur P, Kapil A, Das B, Dhawan B (2002). Prevalence of extended spectrum beta lactamase producing Gram negative bacteria in a tertiary care hospital. Indian. J. Med. Res. 115:153-157.

Mishra SK, Acharya J, Kattel HP, Koirala J, Rijal BP, Pokhrel BM (2012). Metallo-beta-lactamase Producing Gram-negative Bacterial isolates. J. Nepal. Health. Res. Counc. 10(22):208-213.

Moland ES, Kim S, Hong SG, Keneeth \& Thomson (2008). Newer $\beta$ lactamases: Clinical \& Laboratory Implication Part 1. Clin. Microbiol. Newslett. 30:71-78.

Nørgaard M (2012). Risk of Infections in Adult Patients with Haematological Malignancies. The Open. Infect. Dis. J. 6(Suppl 1: M4):46-51.

Noyal MJC, Menezes GA, Harish BN, Sujatha S, Parija SC (2009). Simple screening tests for detection of carbapenemases in clinical isolates of nonfermentative Gram-negative bacteria. Indian. J. Med. Res. 129:707-712.

Pai H, Kang Cl, Byeon JH, Lee KD, Park WB, Kim HB, Kim EC, Oh MD, Choe KW (2004). Epidemiology and clinical features of bloodstream infections caused by AmpC-type-beta-lactamase-producing Klebsiella pneumoniae. Antimicrob. Agents. Chemother. 48(10):3720-3728.

Perez-Perez FJ, Hanson ND (2002). Detection of plasmid-mediated AmpC beta-lactamase genes in clinical isolates by using multiplex PCR. J. Clin. Microbiol. 40:2153-2162.

Philippon A, Arlet G, Jacoby GA (2002). Plasmid-determined Amp C type $\beta$-lactamases. Antimicrob. Agents. Chemother. 46:1-11.

Taneja N, Rao P, Arora J, Dogra A (2008). Occurrence of ESBL \& Amp$\mathrm{C}$ b-lactamases \& susceptibility to newer antimicrobial agents in complicated UTI. Indian. J. Med. Res. 127:85-88.

Uma Karthika R, Srinivasa Rao R, Sahoo S, Shashikala P, Kanungo R, Jayachandran S, Prashanth K (2009). Phenotypic and genotypic assays for detecting the prevalence of metallo-beta-lactamases in clinical isolates of Acinetobacter baumannii from a South Indian tertiary care hospital. J. Med. Microbiol. 58:430-435.

Upadhyay S, Sen MR, Bhattacharjee A (2010). Presence of different beta-lactamase classes among clinical isolates of Pseudomonas aeruginosa expressingAmpC beta-lactamase enzyme. J. Infect. Dev. Ctries. 4(4):239-242.

Varaiya A, Kulkarni N, Kulkarni M, Bhalekar P, Dogra J (2008). Incidence of metallo beta lactamase producing Pseudomonas aeruginosa in ICU patients. Indian. J. Med. Res. 127:398-402.

Yong D, Lee K, Yum JH, Shin HB, Rossolini GM, Chong Y (2002). Imipenem-EDTA disk method for differentiation of metallo-betalactamase-producing clinical isolates of Pseudomonas spp. and Acinetobacter spp. J. Clin. Microbiol. 40:3798-3801.

Zavasci, AC, Carvalhaes CG, Picao RC and Gales AC (2010). Multidrug resistant Pseudomonas aeruginosa and Acintobacter baumannil resistance mechanisms and implications for therapy. Expert. Rev. Anti. Infect. Ther. 8:71-93. 